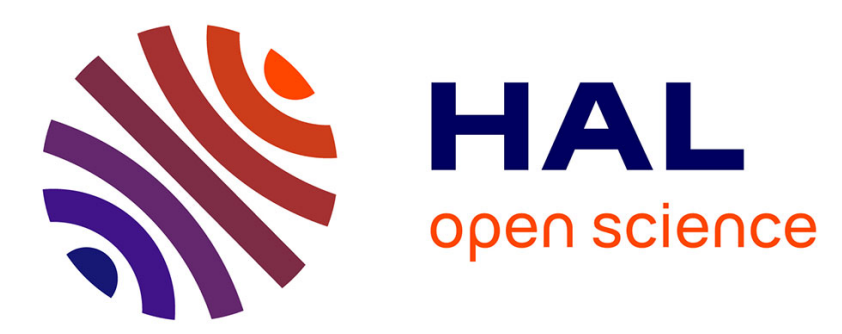

\title{
Stage-II fatigue crack growth model from 3D dislocation dynamics simulations
}

C. Déprés, Z. Yang, C. Robertson

\section{To cite this version:}

C. Déprés, Z. Yang, C. Robertson. Stage-II fatigue crack growth model from 3D dislocation dynamics simulations. Philosophical Magazine, In press, Part A: Materials Science, pp.1-18. 10.1080/14786435.2021.2009135 . cea-03483622

\section{HAL Id: cea-03483622 https://hal-cea.archives-ouvertes.fr/cea-03483622}

Submitted on 16 Dec 2021

HAL is a multi-disciplinary open access archive for the deposit and dissemination of scientific research documents, whether they are published or not. The documents may come from teaching and research institutions in France or abroad, or from public or private research centers.
L'archive ouverte pluridisciplinaire HAL, est destinée au dépôt et à la diffusion de documents scientifiques de niveau recherche, publiés ou non, émanant des établissements d'enseignement et de recherche français ou étrangers, des laboratoires publics ou privés. 


\title{
Stage-II fatigue crack growth model from 3D Dislocation Dynamics simulations
}

\author{
C. Déprés ${ }^{\mathrm{a}}, \mathrm{Z} . \mathrm{YANG}^{\mathrm{b}}$ and C. Robertson ${ }^{\mathrm{b}}$ \\ ${ }^{a}$ Laboratoire SYstemes et Matériaux pour la MEcatronique, Université de Savoie, BP80439, \\ 74944 Annecy-le-Vieux Cedex, France; 'b Service de Recherche de Métallurgiques Appliquée, \\ CEA Saclay, 91191 Gif-sur-Yvette, Paris, France
}

\section{ARTICLE HISTORY}

Compiled May 31, 2021

\begin{abstract}
Stage-II fatigue crack propagation in FCC metals is investigated using 3D Discrete Dislocation Dynamics (DD) simulations. The calculations show that dislocation/grain-boundary interaction affects slip dispersion everywhere in the grain, including in the crack tip region. The results are analysed and drawn in the form of simple, quantitative mathematical expressions, depending on a set of physical variables. This approach helps it developing a comprehensive crack propagation model, where the crack growth rate dadN depends on both the crack tip opening displacements and the tip-related nucleation of nano-cavities. It is shown that the modelled crack response is compatible with the well-known Paris expression, which we further interpreted as a ratio between the energy stored in the tip region over the energy spent extending the crack surfaces. The model validity is finally evaluated by comparison with relevant experimental evidence.
\end{abstract}

\section{KEYWORDS}

dislocation; fatigue; simulation; crack; crack growth

\section{Introduction}

Cyclic slip localization and persistent slip bands (PSBs) formation in 316L stainless steel have been extensively investigated and characterized, using various experimental techniques $[1,2,3]$. Precise examinations of persistent slip markings have shown that fatigue crack initiations mainly occur at the PSB-matrix interface [3, 4, 5], or within the PSB itself $[5,6]$. Initiated cracks then propagate and cut through the first grain, during Stage I crack growth [7, 8]. This phase is controlled by the crack tip sliding displacements (CTSD) [9, 10]. Grown-up Stage I cracks then interact with grain boundaries, acting as a microstructural barriers. This is where Stage I crack growth rate slows down (or even arrest), depending on the loading conditions [11]. Propagation resumes as stage-II cracks are initiated and then grow according to the well-known Paris expression [12].

Earlier 2-dimensional dislocation dynamics studies were able to capture important aspects of cyclic plasticity and stage II crack growth $[10,11,12,13,14,15,16,17,18$, $19,20]$. On the other hand, $2 \mathrm{D}$ simulations do not include many important features such as line tension, cross-slip or more generally, the 3D character of the fatigue-related dislocation microstructures. Very few 3-dimensional DD simulations adapted to cyclic 
Table 1. Material parameters (at $300 \mathrm{~K}$ ) for DD simulations of fatigue loading conditions in grade 300 austenitic steel grains. These values were determined thanks to several, earlier investigations.

\begin{tabular}{|c|c|c|c|c|c|c|}
\hline $\begin{array}{c}\text { Cross-slip } \\
\text { threshold } \\
\text { stress } \\
(M P a)\end{array}$ & $\begin{array}{c}\text { Viscous } \\
\text { Drag } \\
\text { coefficient } \\
\left(\times 10^{-5} \text { Pa.s }\right)\end{array}$ & $\begin{array}{l}\text { Lattice } \\
\text { friction } \\
\text { stress } \\
(M P a)\end{array}$ & $\begin{array}{l}\text { Shear } \\
\text { modulus } \\
(\mathrm{MPa})\end{array}$ & $\begin{array}{c}\text { Burgers } \\
\text { vector } \\
\text { magnitude } \\
(\AA)\end{array}$ & $\begin{array}{c}\text { Time } \\
\text { step }(s)\end{array}$ & $\begin{array}{c}\text { Activation } \\
\text { volume }\end{array}$ \\
\hline 51.2 & 1.06 & 40 & 81000 & 2.54 & $2.10^{-10}$ & $1800 b^{3}$ \\
\hline
\end{tabular}

loading conditions have been carried out so far [19, 20, 21]. For this and other reasons, there are still many open questions regarding trans-granular fatigue crack propagation, especially in poly-crystalline materials. Our goal in this work is to investigate stage-II crack propagation using DD simulations accounting for the inherent complexity of the 3D space, including the barrier effect due to grain boundaries.

The DD simulation results help it developing a particular physically-based model describing stage II crack propagation in a broad range of fatigue conditions. This approach is carried out with a view to evaluate the impact of aggravating factors on the fatigue lifetime, to be addressed in a separate set of articles. The present paper focuses on the preliminary model developments and is organized as follows. In section 2 , we briefly recall the DD simulation setup enabling the investigation of stage II crack plasticity mechanisms $[22,23]$. The simulation results are presented in section 3 , in the form of dislocation structure and crack tip displacement evolutions, at the scale of single FCC grains. A corresponding stage II crack propagation model is developed and proposed in section 4, enabling direct comparison with actual crack growth results.

\section{Simulation and investigation methods}

This paper takes advantage of numerical TRIDIS dislocation dynamics (DD) simulations, where the dislocation lines are treated as discrete edge-screw segments [24]. In FCC metals, the dislocation segment velocity is proportional to the local effective stress; itself a superimposition of the applied and internal stress contributions. The input parameters suitable for the investigation of cyclic plasticity in austenitic steel are listed in Table 1 below. Interaction with other dislocations (annihilations, junctions) and glide plane change due to cross-slip are evaluated and updated at each time step. TRIDIS code has been successfully applied and validated in different cases of monotonic loading conditions such as tensile straining [25], nano-indentation [26]. 3D fatigue simulations have been carried out in both defect-free $[19,20,27]$ and cracked grains $[22,23]$.

The 3D simulation setup used in this work is very similar to that used in reference [22, 23] and for this reason, is only briefly recalled in the rest of this section. For instance, the grain geometry is taken as a hexagonal prism with a height to circumscribed diameter ratio $=1$ (see Fig. 1a and $1 \mathrm{~b}$ ). This grain has impenetrable grain boundaries and one free surface, where mobile dislocations can escape and print surface slip markings. The simulation cell acts as an elastic-plastic medium (grain) embedded in an infinite elastic continuum. This assumption is fully relevant in the stage-II fatigue regime, where plasticity is confined within the crack tip region, while the surrounding grains are partially unloaded due to the crack shadowing effect [28, 29, 30]. Stage II fatigue cracks are implemented as a combination of:

(1) 2 crack free surfaces (the crack lips: see Fig. 1)

(2) a crack-induced heterogeneous stress field [6], acting in the surrounding cracked 


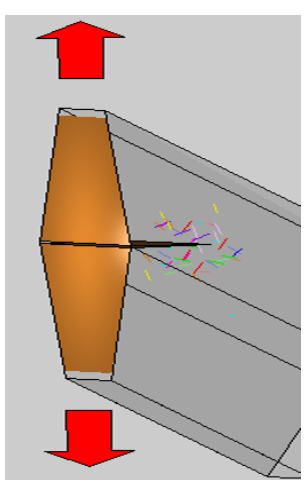

(a) Initial dislocation structures for stageII, random dislocation sources.
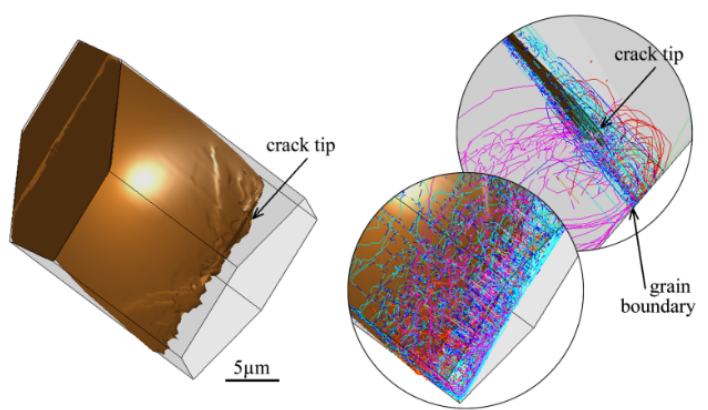

(b) Details of dislocation-mediated plasticity mechanisms controlling the crack-tip opening displacements. Out of crack plane plastic strain spreading due to cross-slip mechanism is in evidence, as the tip draws near the grain boundary.

Figure 1. Dislocation dynamics simulation cases adapted crack propagation.

grain:

$$
\sigma_{i j}(r, \theta)=\frac{K_{I}}{\sqrt{2 \pi r}} f_{i j}(\theta)+\frac{K_{I I}}{\sqrt{2 \pi r}} g_{i j}(\theta)+\frac{K_{I I I}}{\sqrt{2 \pi r}} h_{i j}(\theta)
$$

All the implemented cracks are orientated normal to the tensile loading direction. As a result, stress intensity factors $K_{I}=K_{I I I}=0$ and $K_{I I}=\sigma \sqrt{\pi a}$ and the crack-induced stress field can be expressed as:

$$
\sigma_{i j}(r, \theta)=\sigma \sqrt{\frac{a}{2 r}} f_{i j}(\theta)
$$

(3) A set of random sources placed at a short distance ahead of the crack tip surfaces (see Fig. 1a).

The initial dislocation sources are a set of pinned segments (at least one source per each of the 12 FCC slip systems), all of similar length and randomly positioned as close as possible to the crack tip region. This is the main difference with earlier simulations adapted to short crack propagation in surface grains, which usually develop in association with pre-existing persistent slip band microstructures. The initial source configuration has no effect on the morphology of the microstructure after sufficient cumulated plastic deformation (generally, one full tension-compression cycle) [6,7,22]. Crack tip displacements due to the dislocation microstructure activity are computed using the specific post-treatment methodology as shown in Fig. 1b (for example) and explained in [31]. Image forces are not included in this work, since their influence on grain-scale plasticity is negligible, given the time and space scale in consideration $[22,32]$. 
Table 2. Stress intensity factors calculated using Table 1 data.

\begin{tabular}{|c|c|c|c|c|c|c|}
\hline$a(\mu m)$ & 8 & 12 & 16 & 仓 & 仓ิ & \\
\hline$\Delta \sigma(M P a)$ & 180 & - & 120 & 110 & 100 & \multirow{2}{*}{$\Delta \epsilon_{p}=1 \times 10^{-4}$} \\
\hline$K_{I}(M P a)$ & 902 & - & 850 & 871 & 868 & \\
\hline$\Delta \sigma(M P a)$ & 200 & 160 & 140 & 120 & 110 & \multirow{2}{*}{$\Delta \epsilon_{p}=2 \times 10^{-4}$} \\
\hline$K_{I}(M P a)$ & 1002 & 982 & 992 & 951 & 955 & \\
\hline$\Delta \sigma(M P a)$ & 250 & 200 & 170 & 150 & 120 & \multirow{2}{*}{$\Delta \epsilon_{p}=3 \times 10^{-4}$} \\
\hline$K_{I}(M P a)$ & 1253 & 1227 & 1205 & 1189 & 1128 & \\
\hline
\end{tabular}

\section{Results}

\subsection{Crack tip plasticity in stage II loading conditions: local stress response}

The cyclic stress response associated with the different plastic strain controlled simulation cases is shown in Fig. 2. The corresponding stabilized applied stress levels are repeated in Table 2 below, showing the relation between the stabilized stress level and the stress intensity factor $K_{I}=\sigma \sqrt{\pi a}$.

For a given fixed plastic strain range, the stress intensity factor $K_{I}$ is mostly independent of the crack depth. This effect is consistent with Eq. 2, where the stress field due to a crack of length $a$ under an applied stress amplitude $\sigma$ is exactly the same as the stress field due to a crack of length $2 a$ under an applied stress $\sigma / \sqrt{2}$. The results presented in this section are consistent with experimental observations [33, 34, 35], i.e. $\left(9 \times 10^{2}<K_{I}<9 \times 10^{3}\right) M P a \sqrt{m}$.

Typical plasticity mechanisms associated with stage II cracks are shown in Fig. 3 for increasing crack lengths and conversely decreasing, tip to grain boundary distance. In these conditions, slip spreads in all directions ahead of the crack tip region and involves different non-coplanar slip systems [22]. The corresponding crack-induced dislocation displacements are mostly reversible, from one cycle to the next. This condition applies to a broad range of low stacking fault FCC materials In practice, the crack-tip surfaces are then cyclically exposed to the environment and therefore, to local adsorption of solute elements $\left(\mathrm{O}_{2}\right.$ or water vapour for example).

This phenomenon decreases the interfacial energy of the cyclically exposed surfaces and for this reason, fatigue cracks is thought to propagate by the successive de-cohesion of (tip-related) nano-sized regions, possibly in the form of nano-cavities [22]. Quasicleavage cavity nucleation is consistent with strong acoustic emission levels reported in low stacking fault energy (SFE) materials [36]. The corresponding stage-II crack propagation rate then directly depends on the crack tip opening displacement (CTOD) amplitude, which is computed based on the present DD simulations, as explained in the next section.

\subsection{Crack tip plasticity in stage II loading conditions and crack propagation: local strain response}

The local strain response analysis is carried out using a specific post treatment calculation procedure, taking advantage of half-cylinder calculation meshes placed at a short distance, down the crack tip (see Fig. 4 below). 


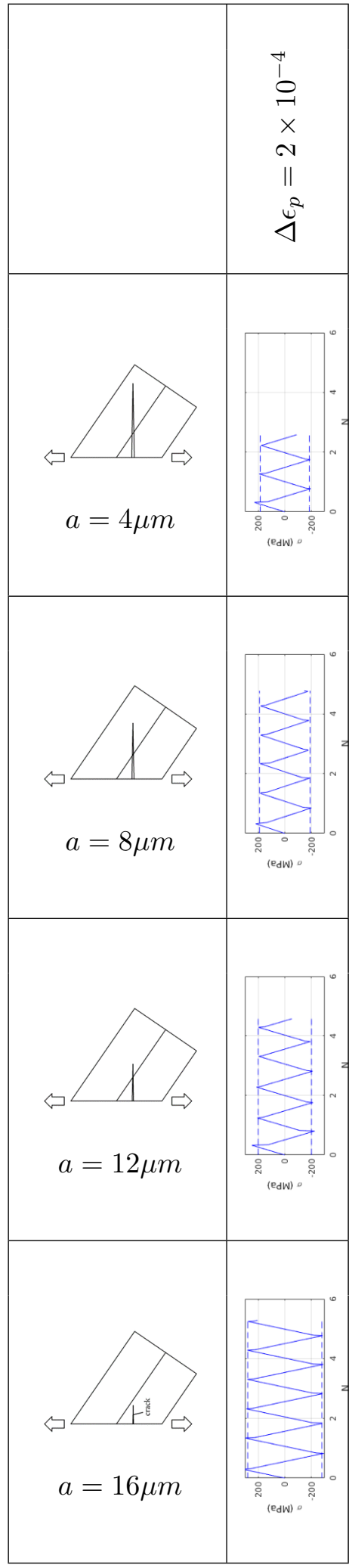

(a) Crack lengths: $a=4,8,12$ and $16 \mu \mathrm{m}$. Crack tip stands at $16,12,8,4 \mu m$ off the grain boundary. $\Delta \epsilon_{p}=2 \times 10^{-4}$.

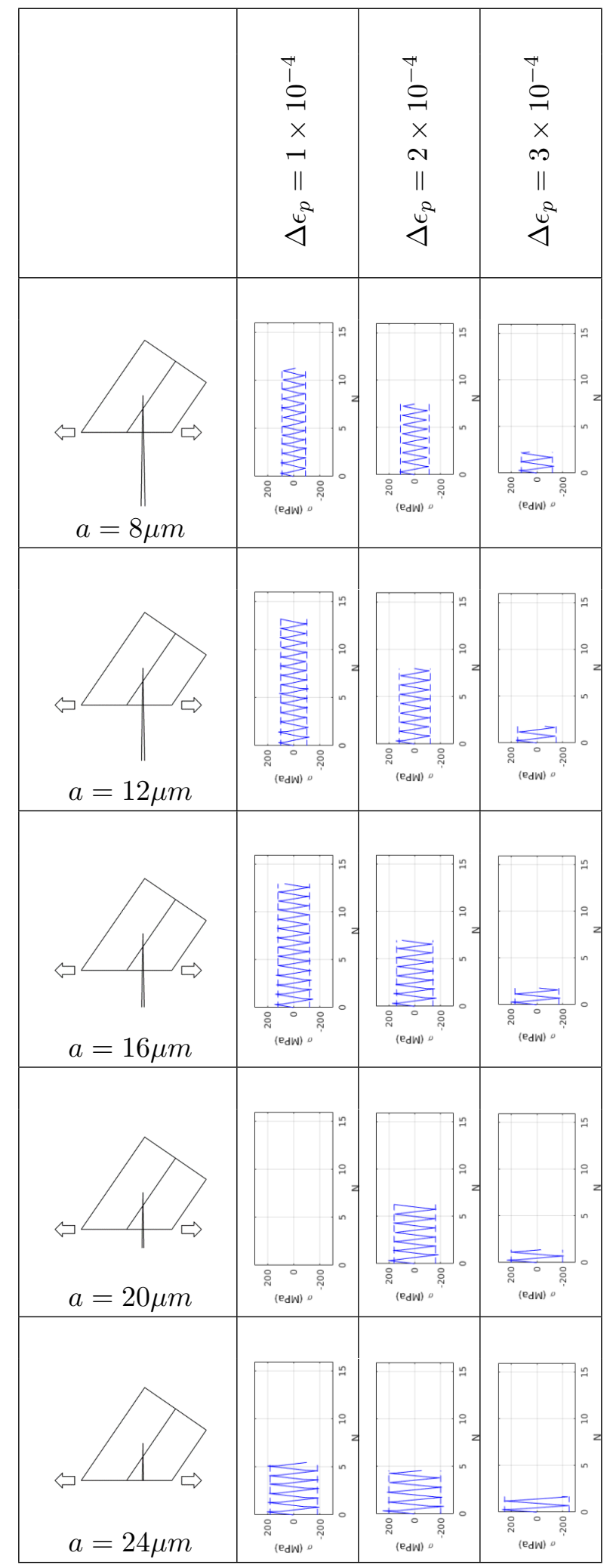

(b) Crack lengths: $a=8,12,16,20$ and $24 \mu \mathrm{m}$. Crack tip stands at $12 \mu \mathrm{m}$ off the grain boundary. $\Delta \epsilon_{p}=1 \times 10^{-4}, 2 \times$ $10^{-4}$ and $3 \times 10^{-4}$.

Figure 2. Applied stress evolutions obtained for different plastic strain ranges and different crack lengths. 


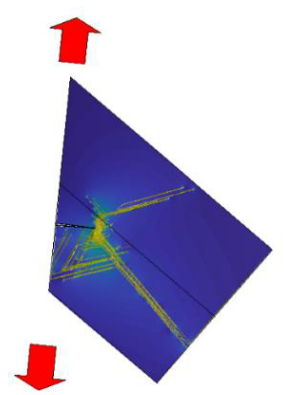

(a)

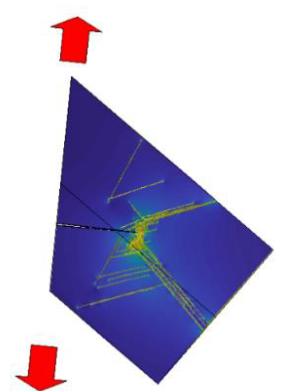

(b)

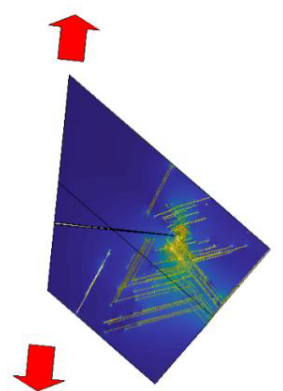

(c)

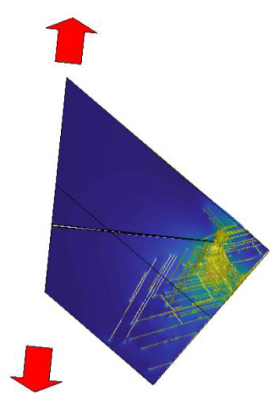

(d)

Figure 3. Cyclic plasticity mechanisms associated with increasing stage II crack depth. Plastic strain involves multiple slip conditions. Plastic strain confinement depends on the crack tip distance to the microstructural barrier (grain boundary), decreasing from (a) through (d) snapshots.

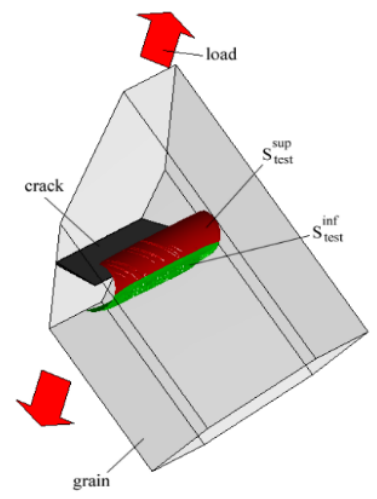

(a) Half-cylindrical mesh position, ahead of the crack front.

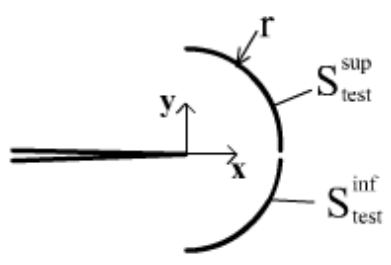

(b) Calculation mesh details. Quantity $r$ is the radius of curvature of the mesh itself.

Figure 4. CTOD evaluation method. 


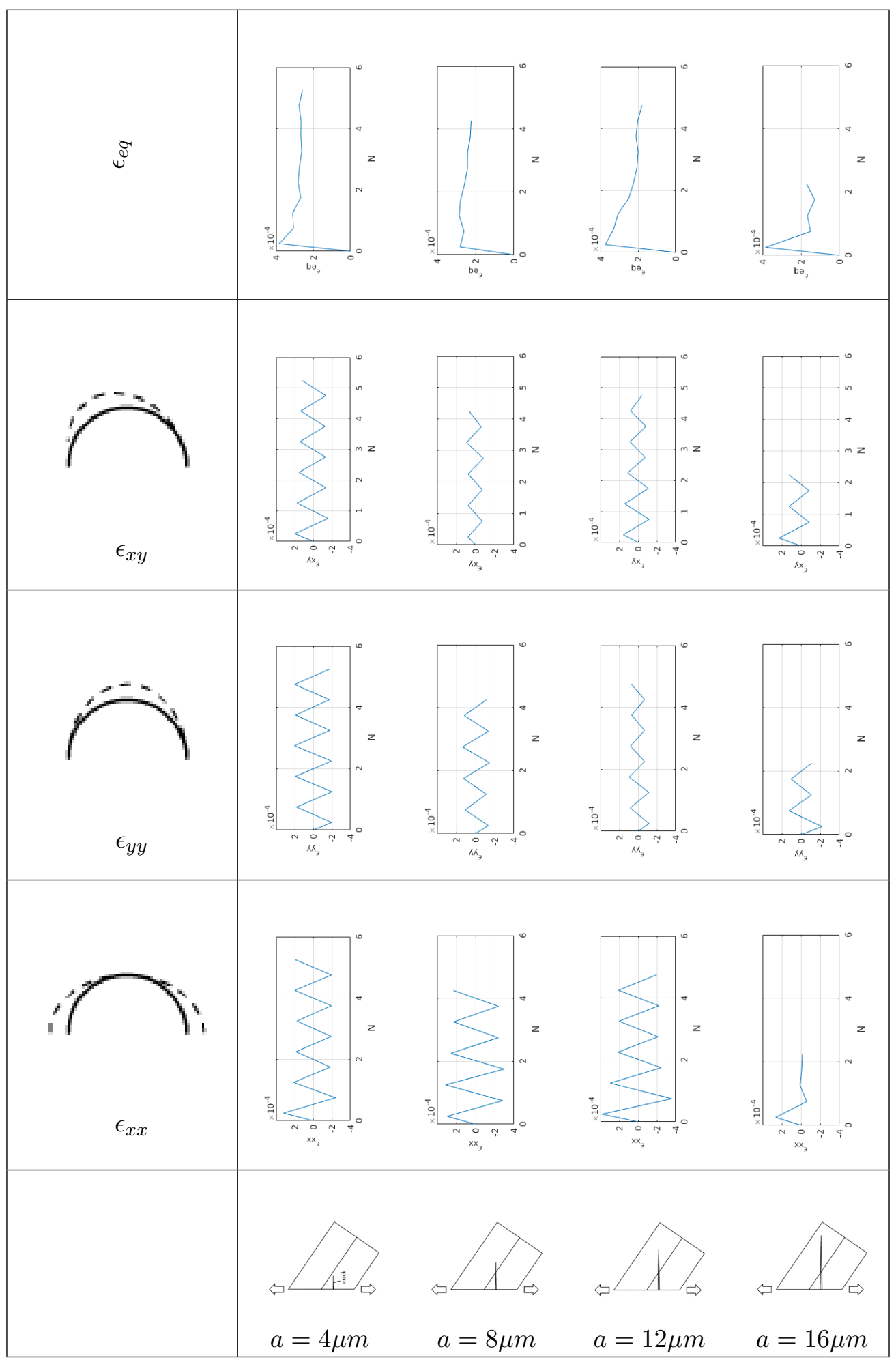

Figure 5. Crack-induced plastic strain for different crack lengths. Strain components $\epsilon_{x x}, \epsilon_{y y}, \epsilon_{x y}$ and equivalent strain $\epsilon_{e q}$ for applied plastic strain range $\Delta \epsilon_{p}=2 \times 10^{-4}$ and different crack lengths: $a=4,8,12$ and $16 \mu \mathrm{m}$. 
The crack-tip induced strain range (noted $\Delta \epsilon_{e q}$ ) is evaluated from the averaged out upper and lower mesh displacements, due to the tip-emitted dislocations. Quantitative crack-induced plastic strain evolutions are given in Fig. 5, for stage II cracks of different lengths, for $\Delta \epsilon_{p}=2 \times 10^{-4}$. The plastic strain components $\epsilon_{x x}, \epsilon_{y y}, \epsilon_{x y}$ and $\epsilon_{e q}$ are defined as:

$$
\begin{aligned}
& \epsilon_{x x}=\frac{\left(\left(u^{\text {sup }}+u^{\text {inf }}\right) x\right)^{\text {moy }}}{r} \\
& \epsilon_{y y}=\frac{\left(\left(u^{\text {sup }}-u^{\text {inf }}\right) y\right)^{\text {moy }}}{2 r} \\
& \epsilon_{x y}=\frac{\left(\left(u^{\text {sup }}-u^{\text {inf }}\right) x\right)^{\text {moy }}}{2 r} \\
& \epsilon_{e q}=\sqrt{\frac{2}{3}\left(\epsilon_{x x}^{2}+\epsilon_{y y}^{2}+2 \epsilon_{x y}^{2}\right)}
\end{aligned}
$$

where $u^{\text {sup }}$ and $u^{\text {inf }}$ are the displacements calculated on the superior and inferior meshes as sketched Fig.2. Those displacements are projected along x (Eqs. 3 and 5) and y (Eq. 4) directions and then averaged out along the whole crack front, i.e. along direction z. The results show that the plastic strain $\epsilon_{e q}$ (Eq. 6) developing near the crack tip stabilizes shortly after completion of the first fatigue cycle (see Fig. 5). Namely, the local plastic strain level is about $\epsilon_{e q}=3 / 2 \Delta \epsilon_{p}$ as long as the crack tip is relatively far-off the grain boundary. The local stabilized plastic strain level is plotted in Fig. 6 (open symbols), showing the crack tip opening defromation evolution representative of stage II fatigue conditions.

Fig. 6 evolution can be described using the following, semi-analytical expression:

$$
\epsilon_{e q}=K_{s} \frac{\epsilon_{p}}{2}\left[1-\exp \left(-\frac{2 \lambda}{\Delta \epsilon_{p}} \frac{b}{D_{g}}\left(1-\frac{a}{D_{g}}\right)\right)\right]
$$

where $K_{s}$ is a dimensionless scaling factor, $\lambda$ is the number of dislocations stored in the crack-tip process zone (averaged out over one complete fatigue cycle), b is the Burgers vector magnitude and $D_{g}$ the grain size (diameter). Eq. 7 includes a growth driving term: $K_{s} \epsilon_{p} / 2$ and a growth mitigation term: $K_{s} \epsilon_{p} / 2 \exp \left(-2 \lambda b / D_{g} \Delta \epsilon_{p}(1-a / D g)\right)$ that scales with the cross-slip probability (or rate) evolution along the tip-emitted shear bands, as the crack front gradually draws near the grain boundary [22].

\section{Stage II crack model from DD simulations: discussion/validation}

\subsection{Main model}

The DD simulation results of Section 3 enable the development of a physically-based crack growth model, applicable to single and poly-crystals. We first suppose that the 


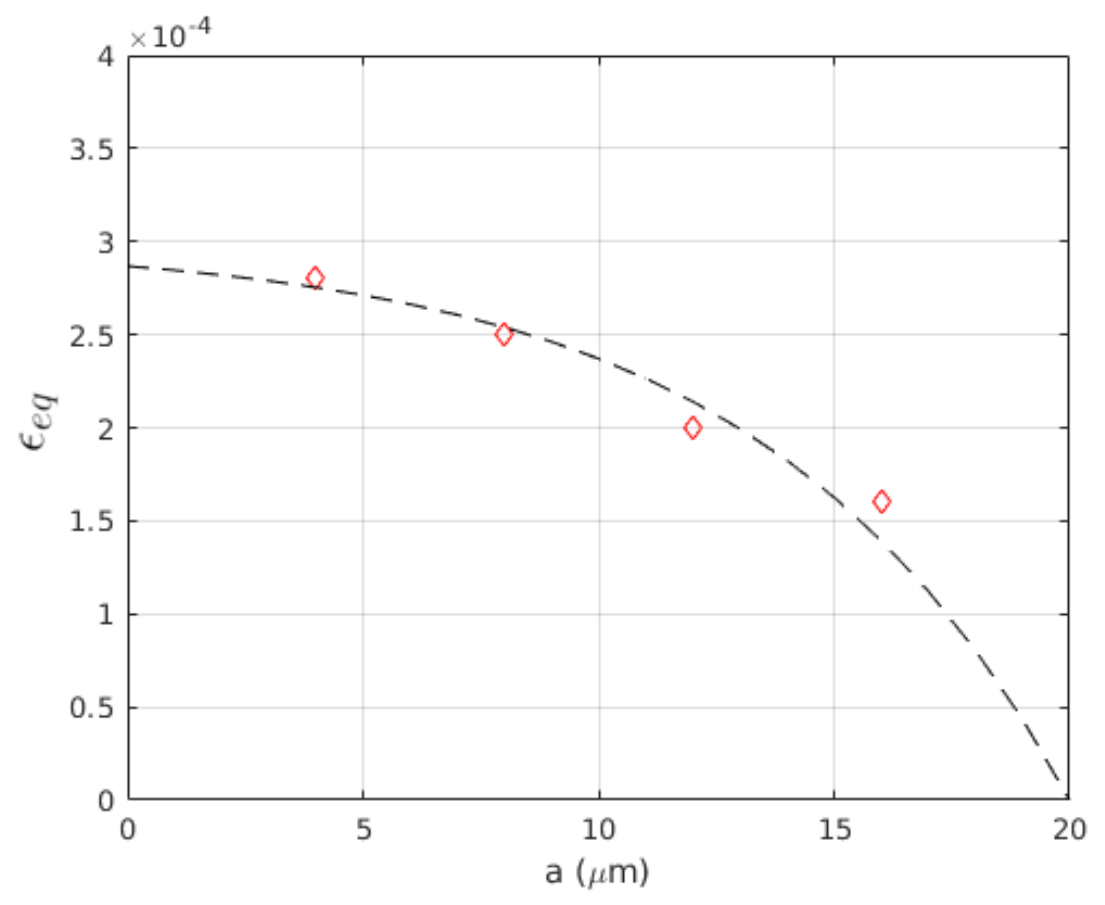

Figure 6. Crack-tip strain $\epsilon_{e q}$ amplitude for increasing crack length. The analytical curve (dashed line) is plotted using Eq.(5) with $\Delta \epsilon=2 \times 10^{-4}, K_{s}=3, D_{g}=20 \mu m, b=2.5 \times 10^{-4} \mu m$ and $\lambda=25$ (dimensionless).

stage II crack growth rate $d a / d N=C T O D / N_{i}$. Based on Eq. (7), we put:

$$
\frac{d a}{d N}=\frac{C T O D}{N_{i}}=\frac{\Delta \epsilon_{e q} D_{g}}{N_{i}}=\frac{\Delta \epsilon_{p}}{N_{i}}\left(1-\exp \left(-\frac{2 \lambda}{\Delta \epsilon_{p}} \frac{b}{D_{g}}\left(1-\frac{a}{D_{g}}\right)\right)\right) D_{g}
$$

where $N_{i}$ is the time to initiation of a micro-cavity (in cycles) at the tip of the crack (see Section 4.2 below). Eq. (8) treats the cracked-grain $\rightarrow$ crack-tip scale transition; where the plastic strain range $\Delta \epsilon_{p}=\Delta \epsilon_{p, l o c a l, w c}$ (reading: local plastic strain, with-crack). For practical reasons, it is suitable to express Eq. (8) in terms of macro-scale variable $\Delta \epsilon_{p, \text { macro }}$ instead of micro-scale $\Delta \epsilon_{p, l o c a l, w c}$. The particular $\Delta \epsilon_{p, l o c a l, w c} \rightarrow \Delta \epsilon_{p, \text { macro }}$ transition can be addressed by using DD simulations comparing the cyclic stress-strain response of cracked versus un-cracked grains, as shown in Section 3 of reference [37]. And hence, combining expressions (11) and (12) of reference [37] leads to:

$$
\Delta \epsilon_{p, l o c a l, w c}=\frac{2 \Delta K_{a p p} \sqrt{\frac{1}{2 r_{0}}}}{\left[\frac{1}{S} \frac{\mu}{1-\nu}\right]\left(1+\frac{\bar{\epsilon}_{p, \text { macro }}}{\Delta \epsilon_{p, \text { macro }}}\right)}\left(1+\frac{\Delta K_{\text {app }}}{\Delta \sigma_{\text {app }}} \sqrt{\frac{1}{2 r_{0}}}\right)
$$

where $S$ is the dimensionless grain shape factor [38], $r_{0}$ a reference distance to the crack tip scaling with the crack-induced plastic zone size, $\Delta K_{a p p}=\Delta \sigma_{a p p} \sqrt{\pi a}$ is the aggregate-scale stress intensity factor and $\epsilon_{p, \text { macro }}$ the macro-scale mean strain amplitude. Inserting Eq. (9) in Eq. (8) assuming $a \gg D_{g}$ stage II cracks and therefore $\Delta K_{a p p} / \Delta \sigma_{a p p} \gg \sqrt{2 r_{0}}$, makes it:

$$
\frac{d a}{d N}=C \Delta K_{a p p}^{2} F^{2}
$$


after re-arrangement. Eq. (10) is similar to the well-known Paris law for a semi-circular crack front, provided:

$$
C=\frac{D_{g}}{2 r_{0} \frac{\mu}{S(1-\nu)}\left(1+\frac{\overline{\epsilon_{p}}}{\Delta \epsilon_{p}}\right) \Delta \sigma_{a p p} N_{i}}
$$

and

$$
F=\sqrt{1-\exp \left(-\frac{r_{0} \frac{\mu}{S(1-\nu)}\left(1+\frac{\overline{\epsilon_{p}}}{\Delta \epsilon_{p}}\right) \Delta \sigma_{a p p}}{\Delta K_{0}^{2}} \frac{\lambda b}{D_{g}}\right)}
$$

putting $(1-a / D g) / \Delta K^{2}=1 / \Delta K_{0}^{2}$ i.e. assuming stable through-grain crack growth; whereas $\Delta K_{0}=\Delta \sigma_{a p p} \sqrt{\pi a_{0}}$ is related to unit crack length $a_{0}$. Stable through-grain crack growth in the i-th grain of a poly-crystal means: $d a / d N_{i}=f\left(D_{g, i}\right)$ for $a \gg D_{g}$. This situation contrasts with Fig. 6 results, where $d a / d N=f\left(a, D_{g}\right)$ for $a<D_{g}$ for $a<D_{g}$.

Quantity $C$ is expressed in $M \mathrm{~Pa}^{-2}$ units and can be interpreted as the (reciprocal) energy spent extending the crack surfaces. Eq. (11) thus calibrates the material resistance against the crack front development per unit fatigue cycle, which physically scales with the surface energy associated with a given test temperature and environment, via parameter $N_{i}$. Quantity $\Delta K_{a p p}^{2} F^{2}=\Delta \sigma^{2} \pi a F^{2}$ is proportional to the effective elastic energy driving the crack growth; whereas the total energy input $\propto \Delta \sigma_{a p p}^{2}$. Eq. (12) thus works as an efficiency factor, tuning the effective crack growth driving force depending on the crack and loading conditions.

\subsection{Cavity nucleation sub-model and comparison with actual fatigue test results}

Direct comparison between (Section 4.1) model predictions and corresponding experimental results requires the explicit evaluation of parameter $N_{i}$ inserted in Eq. (11). In this paper, we assume that quantity $N_{i}$ is controlled by local crystallographic decohesion, as explained in Section 3.1. This particular crack growth mechanism involves cavity nucleation in the crack tip region, depending on the local stress and energy conditions $[20,39,40,41]$. Quantity $N_{i}$ can be appraised by solving the following, (local, tip-related) stress balance expression:

$$
\tau_{0}+\left(\frac{d \tau_{\text {int }}}{d N}\right) N_{i}=\tau_{\text {crit }}\left(\gamma_{\text {surf }}\right)
$$

where $\tau_{\text {crit }}\left(\gamma_{\text {surf }}\right)$ is a critical nano-cavity nucleation stress at the crack tip (to be detailed below); $\tau_{0}$ the stress level initially acting at the crack tip scale and $d \tau_{\text {int }} / d N$ the rate of evolution of local, internal stress [42]. We may then write:

$$
\frac{d \tau_{\text {int }}}{d N}=\frac{d \tau_{\text {int }}}{d y} \frac{d y}{d N_{\text {cycle }}}
$$

where $d \tau_{\text {int }} / d y$ evolution depends on a simple decay function $\tau_{\text {int }}=-\tau_{\text {app }} \exp \left(-2 k \frac{|y|}{D_{g}}\right)$ describing the long-range stress landscape due to individual shear bands (see Fig. 4 of 
reference [19], for example). We can then rewrite Eq. (14) as:

$$
\frac{d \tau_{i n t}}{d y}=-2 \tau_{a p p} \frac{k}{D_{g}} \exp \left(-2 \frac{k y_{0}}{D_{g}}\right)
$$

where the tip-driven plastic zone size $y_{0} \leq 1 / 2 \mu \lambda b / \pi(1-\nu) \tau_{M A X}$ i.e. the sub-band dislocation pile-up size. We then obtain:

$$
\frac{d \tau_{\text {int }}}{d N}=-2 \tau_{\text {app }} \frac{k}{D_{g}} \exp \left(-2 \frac{k y_{0}}{D_{g}}\right) \frac{d y}{d N_{\text {cycle }}}
$$

where $d y / d N_{\text {cycle }}$ characterizes (intra)PSB evolution. Quantity $d y / d N_{\text {cycle }} \approx 1.5$ to 6 $\mathrm{nm} /$ cycle is obtained by solving Eq. (16) using $d \tau_{\text {int }} / d N_{\text {cycle }} \approx 5$ to $12 \mathrm{MPa} /$ cycle from reference [20]. Quantity $d y / d N_{c y c l e}$ is grain-size and load independent in a broad range of fatigue conditions, as far as crack-related plasticity is controlled by shear band nucleation and activity (glide). We may then estimate the critical crack (or nano-cavity) emission stress $\tau_{\text {crit }}\left(\gamma_{\text {surf }}\right)$ in Eq. (13) using Griffiths theory of crack stability, where

$$
\tau_{\text {crit }, 0} \approx \sqrt{\mu\left[\pi /\left(1-\nu^{2}\right)\right]\left(\gamma_{\text {surf }, 0} / a_{\text {Griffith }, 0}\right)}
$$

is associated with reference surface energy $\gamma_{\text {surf }, 0}$ and crack/cavity size $a_{\text {Griffith }, 0}$ [20], in a reference test temperature and chemically inert environment (in vacuum, for example). Further assuming the following energy balance condition:

$$
a_{\text {Griffith }, 0}\left(\tau_{\text {app }}-\tau_{\text {crit }, 0}\right)=\gamma_{\text {surf }, 0}
$$

allows inserting Eq. (17) in Eq. (18) and solving the resulting expression for $a_{\text {Griffith }}$. Stress $\tau_{\text {crit }}$ is then calculated using:

$$
\tau_{\text {crit }} \approx \sqrt{\mu\left[\pi /\left(1-\nu^{2}\right)\right]\left(\gamma_{\text {surf }} / a_{\text {Griffith }, 0}\right)}
$$

depending on the actual (environment and temperature-dependent) surface energy $\gamma_{\text {surf }}$, during a particular test. Stress $\tau_{\text {crit }}$ from Eq. (19) is then inserted in Eq. (13), that is subsequently solved for $N_{i}$ using $\tau_{0}=0$. Quantity $1 / N_{i}$ scales with the number of nano-cavities nucleated per cycle, so the crack growth rate scales with $a_{\text {Griffith }, 0} / N_{i}$. A quantitative evaluation of our crack growth model is compared with actual experimental observations [43], using Table 3 input and different $\gamma_{s u r f}$ values.

The crack size evolution and lifetime is consistent with its experimental counterpart in air at room temperature, for effective grain size $D_{g}=20 \mathrm{~m}$ and $\left(0.085<\gamma_{\text {surf }}<\right.$ $0.22) \mathrm{J} / \mathrm{m}^{2}$. These $\gamma_{\text {surf }}$ values are consistent with the surface energy obtained using atomistic calculations, including a significant concentration of solute atoms [47, 48, 49]. Grain to grain variations of the growth rate may affect the fatigue lifetime scattering, however. This influence is associated with the grain size and orientation distributions, through Eqs. (8)-(19). This particular issue will be addressed in a forthcoming article, presenting a stochastic evaluation of this model using grain size and orientation distribution of an actual, macro-scale grain aggregate. 
Table 3. Fatigue life model input adapted to grade 300 austenitic steels. Quantity $N_{i}$ is calculated using Eqs. 13-18 with different $\gamma_{s u r f}$ values. Relevant $y_{0}, d \tau_{i n t} / d N_{c y c l e}$ and $d y / d N_{c y c l e}$ ranges are specified in the main text. Reference distance ranges $0.2 D_{g}<r_{0}<0.5 D_{g}$ in consistence with experimental observations [44]. Stress range $\Delta \sigma \approx 535 \mathrm{MPa}$ consistent with the cyclic stress-strain curve for $\Delta \epsilon_{p, \text { macro }}=10^{-3}$ as reported in $[45,46]$, for $\bar{\epsilon}_{p, \text { macro }}=0$.

\begin{tabular}{ccc}
\hline Parameter & Value & Unit \\
\hline$S$ & 0.66 & - \\
$\mu$ & $8.4 \times 10^{10}$ & $P a$ \\
$\nu$ & 0.3 & - \\
$\overline{\epsilon_{p}}$ & 0 & - \\
$\Delta \epsilon_{p}$ & $10^{-3}$ & - \\
$\Delta \sigma$ & 535 & $M P a$ \\
$\lambda$ & 25 & - \\
$b$ & $2.5 \times 10^{-10}$ & $m$ \\
$N_{i}$ & $50-200$ & cycles \\
\hline
\end{tabular}

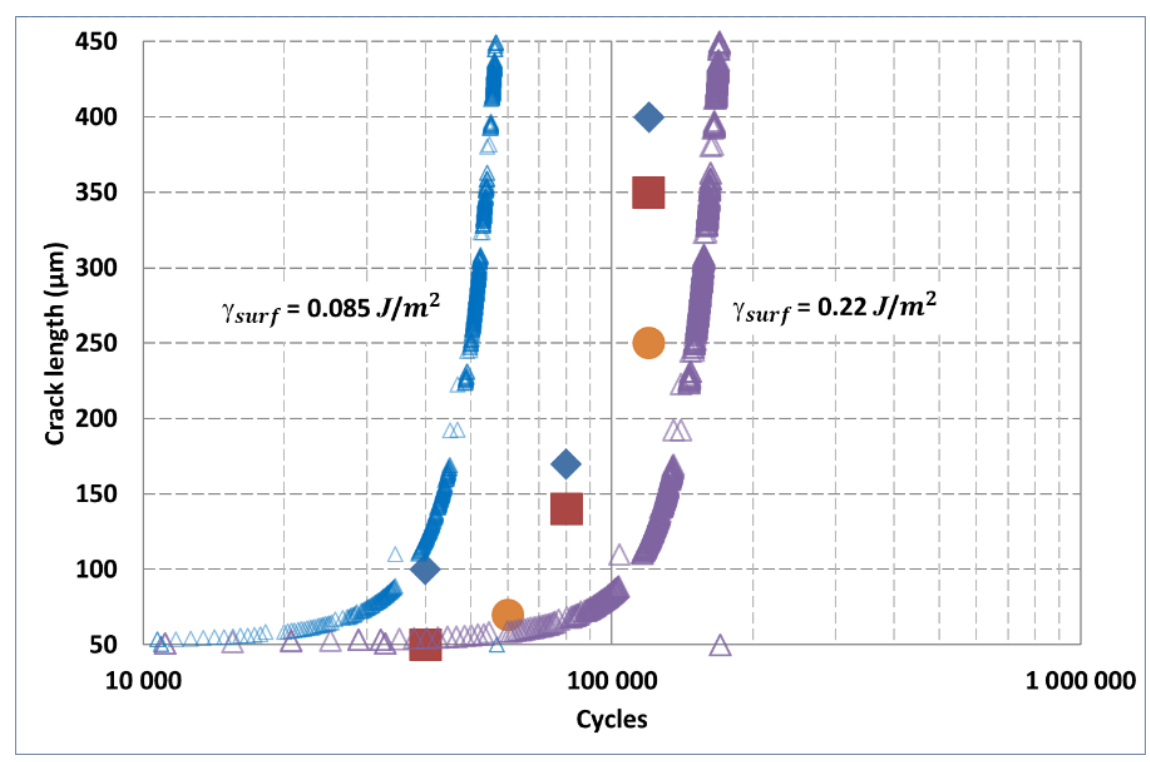

Figure 7. Fatigue model comparison with relevant experimental observations. Solid symbols: actual crack observations in fatigue specimens tested at room temperature, under controlled plastic strain conditions $\Delta \epsilon_{p, \text { macro }}=10^{-3}$. Open symbols: theoretical crack growth prediction assuming fixed effective grain size $D_{g}=20 \mu \mathrm{m}$ and crystallographic orientation, for simplicity. The crack length evolutions are calculated by integration of Eq. 10 using small, randomized crack length increments. The initial crack length considered is $a=2 D_{g}$ and initial number of cycles $N_{\text {cycles }}=40000$ to account for the crack initiation stage.

\section{Conclusions}

This paper presents a stage-II crack propagation model based on dislocation-mediated plasticity mechanisms, from three-dimensional DD simulation results adapted to grade 300 austenitic steels. The crack growth rate calculations include 2 distinct top-down scale transitions: i-from polycrystalline aggregate to cracked grain, ii-from cracked grain to crack-tip opening displacements. The main results drawn from the present investigation are as follows.

- Crack-induced plasticity in low-stacking fault energy FCC materials involves 
highly reversible dislocation microstructures, in the form of shear bands.

- The corresponding stage II crack propagation mechanism is consistent with the progressive de-cohesion of nano-sized grain regions, in the crack tip process region.

- A univocal relation is existing between the plastic strain range and crack tip plasticity mechanisms. This relation helps establishing a crack propagation rule comparable Paris expression, which can be interpreted as an effective, stored/dissipated energy ratio.

- Quantitative model predictions and comparison with actual experimental evidence on macro tests entail the development of a cavity sub-model, characterized by parameter $N_{i}$.

- Parameter $N_{i}$ is calculated based on surface energy and the internal stress landscape at the scale of the individual, tip-related shear bands. Relevant quantities $d y / d N_{c y c l e}$ and $y_{0}$ and $r_{0}$ are evaluated based on DD simulations and/or selected experimental data.

- Our plasticity model and cavity nucleation sub-model combined allows predicting the stage-II crack growth rate, depending on loading $\left(\Delta \sigma, \Delta \epsilon_{p, \text { macro }}\right)$ and microstructural $\left(D_{g}\right)$ parameters. The predictions are successfully compared with corresponding observation data.

The present physically-based approach requires very modest computational resources and is especially suitable to evaluate the impact of various aggravating factors (ratcheting, variable loading amplitude, grain size and orientation distribution, environment and testing temperature conditions, etc), on stage II crack propagation. This approach is developed with a view to help optimizing the laboratory testing effort, while providing a comprehensive interpretation of the fatigue life limiting causes. In a forthcoming paper, we will attempt to explain how to generate systematic data for fatigue design based on various experimental sources and calculation results.

\section{Acknowledgements}

This work has been carried out within the framework of the EUROfusion Consortium and has received funding from the Euratom research and training programme 20142018 and 2019-2020 EDDI under Grant Agreements No. 633053 and No. 755039. The views and opinions expressed herein do not necessarily reflect those of the European Commission. The complementary support of the Materials Research Program VALO of the Nuclear Energy Division; French Atomic Energy Commission (CEA/DEN), is acknowledged as well.

\section{References}

\section{References}

[1] T. Kruml, J. Polatk, K. Obrtlitk, and S. Degallaix, Dislocation structures in the bands of localised cyclic plastic strain in austenitic $316 l$ and austenitic-ferritic duplex stainless steels, Acta Materialia 45 (1997), pp. 5145-5151, Available at https://www. sciencedirect.com/science/article/pii/S135964549700178X.

[2] J. Man, K. Obrtlík, C. Blochwitz, and J. Polák, Atomic force microscopy of surface relief in individual grains of fatigued $316 l$ austenitic stainless steel, Acta Materi- 
alia 50 (2002), pp. 3767-3780, Available at https://www.sciencedirect.com/ science/article/pii/S1359645402001672.

[3] J. Man, T. Vystavl, A. Weidner, I. Kubna, M. Petrenec, T. Kruml, and J. Polák, Study of cyclic strain localization and fatigue crack initiation using fib technique, International Journal of Fatigue 39 (2012), pp. 44-53, Available at https://www . sciencedirect.com/science/article/pii/S0142112311001150, physical and phenomenological approaches to fatigue damage.

[4] M. Bao-Tong and C. Laird, Overview of fatigue behavior in copper single crystalsi. surface morphology and stage $i$ crack initiation sites for tests at constant strain amplitude, Acta Metallurgica 37 (1989), pp. 325-336, Available at https://www . sciencedirect.com/science/article/pii/0001616089902174.

[5] J. Ahmed, A. Wilkinson, and S. Roberts, Ecci characterisation of dislocation structures associated with extrusion/intrusion systems and fatigue cracks in copper single crystals, Phil. Mag. A 81 (2001), pp. 1473-1488.

[6] K. Katagiri, A. Omura, K. Koyanagi, J. Awatani, T. Shiraishi, and H. Kaneshiro, Early stage crack tip dislocation morphology in fatigued copper, Metallurgical Transactions A 8 (1977), pp. 1769-1773.

[7] J. Ahmed, A. Wilkinson, and S. Roberts, Study of dislocation structures near fatigue cracks using electron channelling contrast imaging technique (ecci), Journal of microscopy 195 (1999), pp. 197-203.

[8] Y. Kaneko, M. Ishikawa, and S. Hashimoto, Dislocation structures around crack tips of fatigued polycrystalline copper, Materials Science and Engineering: A 400 (2005), pp. 418-421.

[9] B.A. Bilby, A.H. Cottrell, and K. Swinden, The spread of plastic yield from a notch, Proceedings of the Royal Society of London. Series A. Mathematical and Physical Sciences 272 (1963), pp. 304-314.

[10] R. Lardner and A.H. Cottrell, Bilby-cottrell-swinden model for a growing crack with residual stresses, Proceedings of the Royal Society of London. A. Mathematical and Physical Sciences 317 (1970), pp. 199-209.

[11] G.P. Reddy, C. Robertson, C. Déprés, and M. Fivel, Effect of grain disorientation on early fatigue crack propagation in face-centred-cubic polycrystals: A threedimensional dislocation dynamics investigation, Acta materialia 61 (2013), pp. 5300-5310.

[12] S. Suresh, Fatigue of materials, Cambridge university press, 1998.

[13] V. Doquet, A first stage in the development of micromechanical simulations of the crystallographic propagation of fatigue cracks under multiaxial loading, Fatigue \& Fracture of Engineering Materials \& Structures 21 (1998), pp. 661-672.

[14] V. Deshpande, A. Needleman, and E. Van der Giessen, Discrete dislocation plasticity modeling of short cracks in single crystals, Acta Materialia 51 (2003), pp. $1-15$.

[15] B. Künkler, O. Düber, P. Köster, U. Krupp, C. Fritzen, and H. Christ, Modelling of the transition from stage $i$ to stage ii short crack propagation, Eng Fract Mech 75 (2008), pp. 715-725.

[16] P. Hansson and S. Melin, Simulation of simplified zigzag crack paths emerging during fatigue crack growth, Engineering fracture mechanics 75 (2008), pp. 14001411.

[17] F. Riemelmoser, R. Pippan, and H. Stüwe, An argument for a cycle-by-cycle propagation of fatigue cracks atsmall stress intensity ranges, Acta materialia 46 (1998), pp. 1793-1799.

[18] C. Bjerkén and S. Melin, Growth of a short fatigue crack-a long term simulation 
using a dislocation technique, International Journal of Solids and Structures 46 (2009), pp. 1196-1204.

[19] C. Déprés, C. Robertson*, and M. Fivel, Low-strain fatigue in aisi $316 l$ steel surface grains: a three-dimensional discrete dislocation dynamics modelling of the early cycles $i$. dislocation microstructures and mechanical behaviour, Philosophical Magazine 84 (2004), pp. 2257-2275.

[20] C. Déprés, C. Robertson, and M.C. Fivel, Low-strain fatigue in $316 l$ steel surface grains: a three dimension discrete dislocation dynamics modelling of the early cycles. part 2: Persistent slip markings and micro-crack nucleation, Philosophical Magazine 86 (2006), pp. 79-97.

[21] C. Heinrich and V. Sundararaghavan, A method to predict fatigue crack initiation in metals using dislocation dynamics, Corrosion Reviews 35 (2017), pp. 325-341.

[22] C. Déprés, G. Prasad Reddy, C. Robertson, and M. Fivel, An extensive 3d dislocation dynamics investigation of stage-i fatigue crack propagation, Philosophical Magazine 94 (2014), pp. 4115-4137.

[23] G. Prasad Reddy, R. Sandhya, K. Laha, C. Depres, C. Robertson, and A. Bhaduri, The effect of the location of stage-i fatigue crack across the persistent slip band on its growth rate-a $3 d$ dislocation dynamics study, Philosophical Magazine 97 (2017), pp. 1265-1280.

[24] M. Verdier, M. Fivel, and I. Groma, Mesoscopic scale simulation of dislocation dynamics in fcc metals: Principles and applications, Modelling and Simulation in Materials Science and Engineering 6 (1998), p. 755.

[25] L. Tabourot, M. Fivel, and E. Rauch, Generalised constitutive laws for fcc single crystals, Materials Science and Engineering: A 234 (1997), pp. 639-642.

[26] M. Fivel, C. Robertson, G. Canova, and L. Boulanger, Three-dimensional modeling of indent-induced plastic zone at a mesoscale, Acta materialia 46 (1998), pp. 61836194.

[27] C. Déprés, M. Fivel, and L. Tabourot, A dislocation-based model for low-amplitude fatigue behaviour of face-centred cubic single crystals, Scripta Materialia 58 (2008), pp. 1086-1089.

[28] J. Rupil, L. Vincent, F. Hild, and S. Roux, Identification and probabilistic modeling of mesocrack initiations in $304 \mathrm{l}$ stainless steel, International Journal for Multiscale Computational Engineering 9 (2011).

[29] J. Rupil, Multi-cracking in uniaxial and biaxial fatigue of $304 \mathrm{l}$ stainless steel, Tech. Rep., Ecole Normale Superieure de Cachan Univ.(France), 2012.

[30] N. Malesys, Probabilistic modeling of crack networks in thermal fatigue; modelisation probabiliste de formation de reseaux de fissures de fatigue thermique (2007).

[31] M. Fivel and C. Depres, An easy implementation of displacement calculations in 3d discrete dislocation dynamics codes, Philosophical Magazine 94 (2014), pp. 3206-3214.

[32] M. Fivel, T. Gosling, and G. Canova, Implementing image stresses in a 3d dislocation simulation, Modelling and Simulation in Materials Science and Engineering 4 (1996), p. 581.

[33] K. Obrtlik, T. Kruml, and J. Polak, Dislocation structures in $316 l$ stainless steel cycled with plastic strain amplitudes over a wide interval, Materials Science and Engineering: A 187 (1994), pp. 1-9.

[34] K. Obrtlık, J. Polák, M. Hájek, and A. Vašek, Short fatigue crack behaviour in $316 l$ stainless steel, International journal of fatigue 19 (1997), pp. 471-475.

[35] J. Polák, K. Obrtlik, and A. Vašek, Short crack growth kinetics and fatigue life of materials, Materials Science and Engineering: A 234 (1997), pp. 970-973. 
[36] D. Harris and H. Dunegan, Continuous monitoring of fatigue-crack growth by acoustic-emission techniques, Experimental Mechanics 14 (1974), pp. 71-81.

[37] G.P. Reddy, C. Robertson, C. Déprés, and M. Fivel, Effect of grain disorientation on early fatigue crack propagation in face-centred-cubic polycrystals: A threedimensional dislocation dynamics investigation, Acta materialia 61 (2013), pp. $5300-5310$.

[38] J. Hirth and J. Lothe, Theory of dislocations, McGraw-Hill, New York, 1982.

[39] A. Van der Ven and G. Ceder, The thermodynamics of decohesion, Acta Materialia 52 (2004), pp. 1223-1235, Available at https://www.sciencedirect.com/ science/article/pii/S1359645403007006.

[40] C.P.B. Jr and E.A.S. Jr, The fatigue crack growth behavior of the alculi alloy weldalite 049, Fatigue \& Fracture of Engineering Materials \& Structures 14 (1991), pp. 103-114.

[41] J. Rice and D. Drucker, Energy changes in stressed bodies due to void and crack growth, International Journal of Fracture Mechanics 3 (1967), pp. 19-27.

[42] T. Mura, A theory of fatigue crack initiation, Materials Science and Engineering: A 176 (1994), pp. 61-70, Available at https://www.sciencedirect.com/science/ article/pii/0921509394909598.

[43] C. Robertson, L. Vincent, S. Paradowski, and P. Villechaise, Projet afgrap : Livrable 3.3.4 micro-propagation des fissures de fatigue dans un acier $316 l$ : effet de lorientation cristallographique et de la contrainte moyenne, Tech. Rep. DEN/DANS/DMN/SRMA/LC2M/NT/2012-3327/A, French Atomic and Alternative Energy Commission, 2012.

[44] C. Robertson, G.V. Prasad Reddy, and C. Déprés, Effect of grain disorientation on early fatigue crack propagation in fcc polycrystals: Dislocation dynamics simulations and corresponding experimental validation, Transactions of the Indian Institute of Metals 69 (2016), pp. 477-481.

[45] A.A. Tavassoli, Dislocation concepts applied to fatigue properties of austenitic stainless steels including time-dependent modes, Philosophical Magazine A 54 (1986), pp. 521-538, Available at https://doi.org/10.1080/ 01418618608243610.

[46] J. POLÁK, K. OBRTLÍK, and M. HÁJEK, Cyclic plasticity in type $316 l$ austenitic stainless steel, Fatigue \& Fracture of Engineering Materials \& Structures 17 (1994), pp. 773-782, Available at https://onlinelibrary.wiley.com/doi/abs/ 10.1111/j.1460-2695.1994.tb00808.x.

[47] M. Rieth, B. Dafferner, and H.D. Röhrig, Embrittlement behaviour of different international low activation alloys after neutron irradiation, Journal of Nuclear Materials 258-263 (1998), pp. 1147-1152, Available at https://www . sciencedirect. com/science/article/pii/S0022311598001718.

[48] K. ichi Ebihara, T. Suzudo, M. Yamaguchi, and Y. Nishiyama, Introduction of vacancy drag effect to first-principles-based rate theory model for irradiation-induced grain-boundary phosphorus segregation, Journal of Nuclear Materials 440 (2013), pp. 627-632, Available at https://www.sciencedirect.com/science/article/ $\mathrm{pii} / \mathrm{S} 002231151300812 \mathrm{X}$.

[49] M. Yamaguchi, First-principles study on the grain boundary embrittlement of metals by solute segregation: Part $i$. iron (fe)-solute (b, $c, p$, and s) systems, Metallurgical and Materials Transactions A 42 (2011), pp. 319-329. 